\title{
Neonatal Rat Hearts Cannot Be Protected by Ischemic Postconditioning
}

\section{J. DOUL ${ }^{1}$, Z. CHARVÁTOVÁ ${ }^{1}$, I. OŠŤÁDALOVÁ ${ }^{3}$, M. KOHUTIAR ${ }^{2}$, H. MAXOVÁ ${ }^{1}$, B. OŠŤÁDAL ${ }^{3}$}

${ }^{1}$ Department of Pathophysiology, Second Faculty of Medicine, Charles University in Prague, Czech Republic, ${ }^{2}$ Department of Medical Chemistry and Clinical Biochemistry, Second Faculty of Medicine, Charles University in Prague and Motol University Hospital, Czech Republic, ${ }^{3}$ Institute of Physiology, Czech Academy of Sciences, Prague, Czech Republic

Received December 12, 2014

Accepted April 10, 2015

On-line June 5, 2015

\section{Summary}

Although there are abundant data on ischemic postconditioning (IPoC) in the adult myocardium, this phenomenon has not yet been investigated in neonatal hearts. To examine possible protective effects of IPoC, rat hearts isolated on days 1, 4, 7 and 10 of postnatal life were perfused according to Langendorff. Developed force (DF) of contraction was measured by an isometric force transducer. Hearts were exposed to 40 or $60 \mathrm{~min}$ of global ischemia followed by reperfusion up to the maximum recovery of DF. IPoC was induced by three cycles of 10,30 or $60 \mathrm{~s}$ periods of global ischemia/reperfusion. To further determine the extent of ischemic injury, lactate dehydrogenase (LDH) release was measured in the coronary effluent. Tolerance to ischemia did not change from day 1 to day 4 but decreased to days 7 and 10. None of the postconditioning protocols tested led to significant protection on the day 10 . Prolonging the period of sustained ischemia to $60 \mathrm{~min}$ on day 10 did not lead to better protection. The $3 \times 30$ s protocol was then evaluated on days 1,4 and 7 without any significant effects. There were no significant differences in LDH release between postconditioned and control groups. It can be concluded that neonatal hearts cannot be protected by ischemic postconditioning during first 10 days of postnatal life.

\section{Key words}

Neonatal rats - Ischemic postconditioning - Tolerance to ischemia • Contractile function • Lactate dehydrogenase

\section{Corresponding author}

J. Doul, Department of Pathophysiology, Second Faculty of Medicine, Charles University in Prague, Plzeňská 130/221, 15006 Prague 5, Czech Republic. E-mail: jan.doul@gmail.com

\section{Introduction}

Myocardial ischemia undoubtedly belongs to the most frequent (and hence the most widely studied) cardiovascular diseases of modern times. Ischemia originates as the disproportion between the amount of oxygen supplied to the cardiac cell and the amount actually required by the cell. The extent of ischemic injury depends, however, not only on the intensity and duration of ischemia but also on the cardiac tolerance to oxygen deprivation. Cardiac sensitivity to hypoxia changes significantly during ontogenetic development: tolerance of the immature heart to acute oxygen deprivation is significantly higher as compared with the adult myocardium (Riva and Hearse 1993, Oštádalová et al. 1998). Thus, the question arises whether we can further increase the already high resistance of the immature mammalian heart. To the most effective experimental protective mechanisms belong long-lasting adaptation to chronic hypoxia (for a review see Ošt'ádal and Kolář 2007) and brief adaptation, so called ischemic preconditioning (for a review see Bolli 2007). Whereas abundant data are available on the two phenomena in adults, the information on the immature heart are only 
sporadic. We have shown previously (Oštádalová et al. 1998) that classical ischemic preconditioning, at least in rats, is absent at birth and the enhanced postischemic recovery of contractile function can be observed only at the end of the first postnatal week. Similar results were obtained after adaptation to chronic hypoxia (Ošt’ádalová et al. 2002).

The protective effect of another phenomenon ischemic postconditioning (Zhao et al. 2003) - is comparable with ischemic preconditioning and was observed in many species, including humans (Laskey 2005). Data on the possible protective effect of postconditioning on the immature heart are still lacking (for a review see Oštádal et al. 2009a). The aim of our study was, therefore, to evaluate the effect of ischemic postconditioning in rats during the first ten days of postnatal development. Since different protocols of ischemic postconditioning were described for adult animals (for a review see Skyschally et al. 2009), several of them were preliminary tested in 10-day-old animals and then employed on the $1^{\text {st }}, 4^{\text {th }}$ and $7^{\text {th }}$ day of postnatal life.

\section{Methods}

All the investigations conform to the European Community and NIH guidelines for using experimental animals (National Academy Press 1996). All procedures were approved by Animal Studies Committee of the Second Faculty of Medicine, Charles University in Prague.

\section{Animal model}

A total of 113 neonatal Wistar rats at the ages of $1,4,7$ and 10 days of both sexes were used throughout the experiments. Experimental and control groups were composed from at least three different litters. All mothers had free access to water and a standard laboratory diet ad libitum.

\section{Heart function}

The animals were weighted and killed by cervical dislocation. The chest was quickly opened and stainless steel cannula (with an external diameter of $0.45 \mathrm{~mm}$ for day 1 and 4 or $0.8 \mathrm{~mm}$ for day 7 and 10 ) was inserted into the aorta. The heart was rapidly excised, the atria were removed and were perfused in the Langendorff mode under constant pressure corresponding to the mean arterial blood pressure for the given developmental stage
(Litchfield 1958, Zicha et al. 1986), i.e. 25, 42, 57 and $73 \mathrm{~cm} \mathrm{H}_{2} \mathrm{O}$ on day $1,4,7$ and 10 , respectively. The hearts were perfused with a Krebs-Henseleit solution containing (in $\mathrm{mmol} / \mathrm{l}$ ): $\mathrm{NaCl} 118.0 ; \mathrm{KCl} \quad 4.7 ; \mathrm{CaCl}_{2} 1.25$; $\mathrm{MgSO}_{4} 1.2 ; \mathrm{NaHCO}_{3} 25.0 ; \mathrm{KH}_{2} \mathrm{PO}_{4} 1.2$; glucose 7.0 and mannitol 1.1. The solution was saturated by a mixture of $95 \% \mathrm{O}_{2}$ and $5 \%$ of $\mathrm{CO}_{2}(\mathrm{pH} 7.4)$ and temperature was maintained at $37^{\circ} \mathrm{C}$. The hearts were electrically stimulated at a rate of 200 beats/min using silver electrodes attached to the base of the heart. The stimulation was performed with pulses of alternating polarity, $1 \mathrm{~ms}$ duration and voltage set at $50 \%$ above the threshold level. The resting force was gradually increased by means of micromanipulator to the level at which the developed force (DF) was approximately $80 \%$ of the maximum force reached at the optimum preload. The contractile function of this isolated heart was measured using an isometric force transducer connected by a glass fiber, two-arm titanium lever and silk suture ( 0.7 metric) to the apex of the heart. The DF (g) and $+\mathrm{df} / \mathrm{dt} \max$ $(\mathrm{g} / \mathrm{min})$ were evaluated automatically from the force signal using an online computer according to Oštádalová et al. (1998).

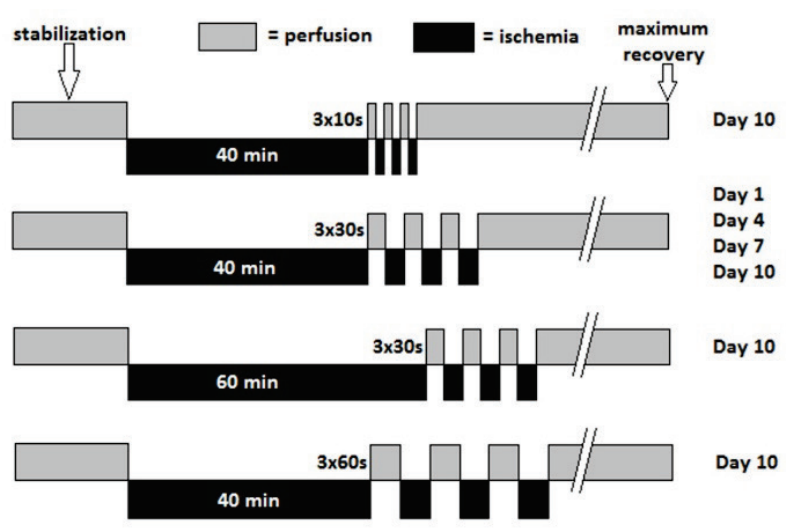

Fig. 1. Scheme summarizing experimental groups and protocols of ischemic postconditioning.

\section{Experimental protocol}

After a period of stabilization, baseline values of DF were recorded. The hearts from each experimental group were exposed to $40 \mathrm{~min}$ of global ischemia, part of hearts was exposed also to prolonged ischemia $(60 \mathrm{~min})$. At the beginning of reperfusion, one-half of the hearts were postconditioned by subjecting them to three $30 \mathrm{~s}$ (10 s or $60 \mathrm{~s}$, respectively) periods of global ischemia, each separated by the period of reperfusion of the same duration (Fig. 1). The remaining hearts were simply 
reperfused up to the maximum recovery of DF (the last value of DF before its decay). DF was measured in all hearts in 3-min intervals during the reperfusion period. Tolerance to ischemia was expressed as a recovery of DF (percentage of baseline values). After the experiment, the hearts were weighed.

\section{LDH measurement}

To further determine the extent of the ischemic injury, the measurement of LDH in the coronary effluent was performed. The samples of effluent were collected at the $1^{\text {st }}, 3^{\text {rd }}, 6^{\text {th }}$ and $12^{\text {th }}$ min of reperfusion and from the rest of the effluent after the end of reperfusion. The amount of effluent was measured by weighing the testtube before and after the sample was taken. Samples for LDH were kept at $+4{ }^{\circ} \mathrm{C}$ until the measurement using the method of Mukherjee (2010): $100 \mu$ lof the sample was incubated with $150 \mu \mathrm{l}$ of freshly prepared $\mathrm{NAD}^{+}$solution $(3 \mathrm{mM})$ and $100 \mu \mathrm{l}$ of lactate $(0.9 \mathrm{M})$ in TRIS-HCl buffer $(0.1 \mathrm{M} ; \mathrm{pH}=9.0)$ at $37^{\circ} \mathrm{C}$ for $15 \mathrm{~min}$, followed by addition of $250 \mu \mathrm{l}$ of 2,4-dinitrophenylhydrazine ( $0.1 \%$ $\mathrm{w} / \mathrm{v}$ in $2 \mathrm{M} \mathrm{HCl}$ ). The reaction was stopped by the addition of $2.5 \mathrm{ml} \mathrm{NaOH}(0.4 \mathrm{M})$ and the absorbance was measured at $505 \mathrm{~nm}$ after $20 \mathrm{~min}$. After quantitative estimation of pyruvate, LDH activity was calculated. Calibration was performed with standard pyruvate solution and evaluated by linear regression.

\section{Statistical analysis}

The results are expressed as means \pm SEM. Each observation of ischemic postconditioning was obtained from at least seven heart preparations in each group. Body weight, heart weight and baseline and recovery of DF values were evaluated by one-way analysis of variance as well as data for the 10 days $40 \mathrm{~min}$ ischemia group. Data from other postconditioned groups as well as the results of LDH release were evaluated by unpaired t-tests. The statistical analyses were performed using StatView 5.0 (SAS Institute, Cary, NC, USA). The results were considered statistically significant when $\mathrm{p}<0.05$.

Table 1. Body weight, heart weight, HW/BW ratio, pre-ischemic DF and df/dt max, means \pm SEM.

\begin{tabular}{|c|c|c|c|c|c|c|c|c|}
\hline Day & & otocol & $\mathbf{n}$ & $\begin{array}{l}\text { Body weight } \\
\text { (g) }\end{array}$ & $\begin{array}{l}\text { Heart weight } \\
\quad(\mathrm{mg})\end{array}$ & $\begin{array}{c}\text { HW/BW } \\
\text { (mg/g) }\end{array}$ & $\begin{array}{l}\text { DF } \\
\text { (g) }\end{array}$ & $\begin{array}{c}\text { Df/dt max } \\
(\mathrm{g} / \mathrm{min})\end{array}$ \\
\hline \multirow{2}{*}{1} & \multirow{2}{*}{\multicolumn{2}{|c|}{$\begin{array}{l}\text { Controls } \\
\text { IPoC } 3 \times 30 \mathrm{~s}\end{array}$}} & 10 & $6.73 \pm 0.19$ & $31.97 \pm 1.52$ & 0.211 & $1.99 \pm 0.11$ & $51.57 \pm 3.32$ \\
\hline & & & 12 & $6.89 \pm 0.16$ & $30.88 \pm 1.16$ & 0.223 & $1.81 \pm 0.12$ & $46.86 \pm 3.00$ \\
\hline \multirow{2}{*}{4} & \multirow{2}{*}{\multicolumn{2}{|c|}{$\begin{array}{l}\text { Controls } \\
\text { IPoC } 3 \times 30 \mathrm{~s}\end{array}$}} & 7 & $9.93 \pm 0.48$ & $50.24 \pm 1.26$ & 0.198 & $2.63 \pm 0.18$ & $65.19 \pm 3.78$ \\
\hline & & & 7 & $10.03 \pm 0.44$ & $53.01 \pm 1.99$ & 0.189 & $2.76 \pm 0.16$ & $66.86 \pm 7.73$ \\
\hline \multirow{2}{*}{7} & \multirow{2}{*}{\multicolumn{2}{|c|}{$\begin{array}{l}\text { Controls } \\
\text { IPoC } 3 \times 30 \mathrm{~s}\end{array}$}} & 8 & $14.80 \pm 0.90$ & $76.90 \pm 2.43$ & 0.192 & $3.85 \pm 0.20$ & $91.54 \pm 4.74$ \\
\hline & & & 10 & $14.69 \pm 0.61$ & $75.15 \pm 2.62$ & 0.195 & $3.56 \pm 0.24$ & $85.97 \pm 4.11$ \\
\hline \multirow{6}{*}{10} & \multirow{4}{*}{$\begin{array}{l}40 \text { min } \\
\text { ischemia }\end{array}$} & Controls & 10 & $21.02 \pm 0.91$ & $102.80 \pm 4.20$ & 0.204 & $6.16 \pm 0.16$ & $148.10 \pm 5.27$ \\
\hline & & IPoC $3 \times 10 \mathrm{~s}$ & 8 & $22.69 \pm 1.04$ & $105.80 \pm 5.29$ & 0.214 & $6.21 \pm 0.31$ & $146.46 \pm 9.27$ \\
\hline & & $\mathrm{IPoC} 3 \times 30 \mathrm{~s}$ & 11 & $20.90 \pm 0.76$ & $99.50 \pm 2.98$ & 0.210 & $6.15 \pm 0.27$ & $146.43 \pm 6.96$ \\
\hline & & IPoc $3 \times 60 \mathrm{~s}$ & 9 & $20.86 \pm 0.83$ & $103.08 \pm 5.24$ & 0.202 & $5.91 \pm 0.14$ & $143.07 \pm 3.61$ \\
\hline & \multirow{2}{*}{$\begin{array}{l}60 \mathrm{~min} \\
\text { ischemia }\end{array}$} & Controls & 11 & $20.41 \pm 0.87$ & $99.63 \pm 3.07$ & 0.205 & $5.42 \pm 0.21$ & $133.21 \pm 7.2$ \\
\hline & & IPoC $3 \times 30 \mathrm{~s}$ & 11 & $21.95 \pm 0.62$ & $103.30 \pm 3.28$ & 0.212 & $5.79 \pm 0.19$ & $141.42 \pm 5.06$ \\
\hline
\end{tabular}

\section{Results}

Tolerance to ischemia and effect of postconditioning

Body and heart weights and baseline contractile parameters are summarized in Table 1. The body and heart weights as well as DF increased during the whole investigated period; there were no differences between control and postconditioned groups. Tolerance to ischemia, expressed as the postischemic recovery of DF, changed significantly during the first ten days of postnatal life. There was no significant difference between 1-day-old and 4-day-old animals; tolerance to ischemia then declined on days 7 and 10 (Fig. 2, gray columns). Three different postconditioning protocols 
were examined in 10-day-old rats. All three failed to significantly improve the recovery of DF (Fig. 3). The increased duration of ischemia $(60 \mathrm{~min})$ and the most powerful protocol of postconditioning found in the previous experiment $(3 \times 30 \mathrm{~s})$ was applied. However, it completely failed to protect the heart (Fig. 4). The same protocol revealed no protective effect on days 1, 4 and 7 (Fig. 2).

\section{LDH release}

Concentrations of $\mathrm{LDH}$ in samples expressed significant negative correlation between the total LDH release and recovery of DF (Fig. 5). There was no difference between postconditioned and control animals on days $1,4,7$ and 10 .

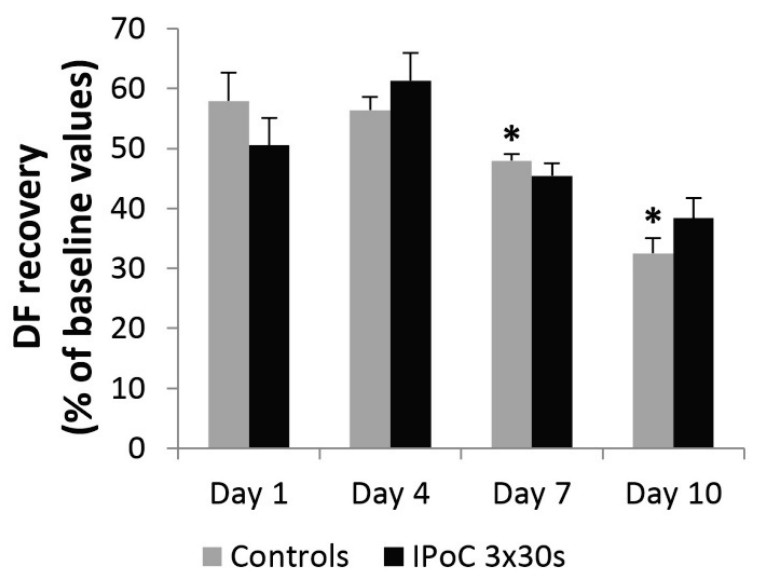

Fig. 2. Tolerance to ischemia (DF, expressed as the percentage of baseline values) and postconditioning (IPoC) during postnatal development. * significantly different $(p<0.05)$ as compared to 1-day-old controls.

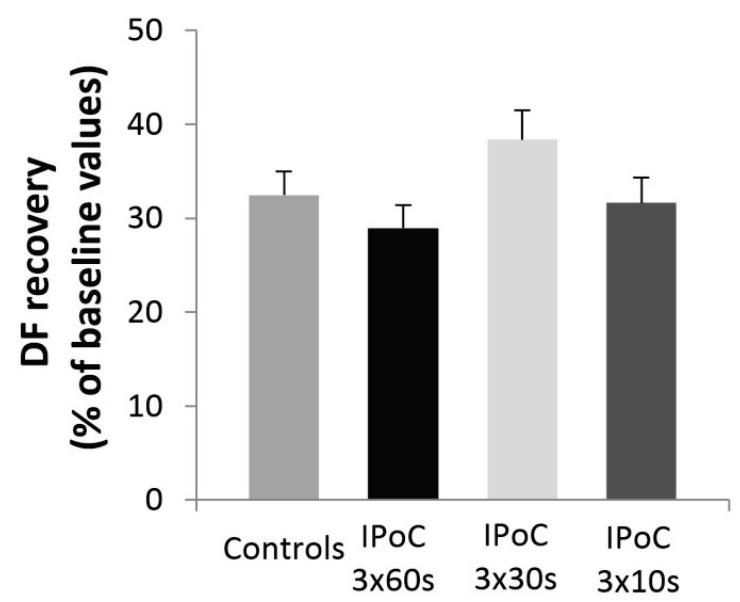

Fig. 3. Tolerance to ischemia (DF, expressed as the percentage of baseline values) and three postconditioning (IPoC) protocols in 10-day-old animals.

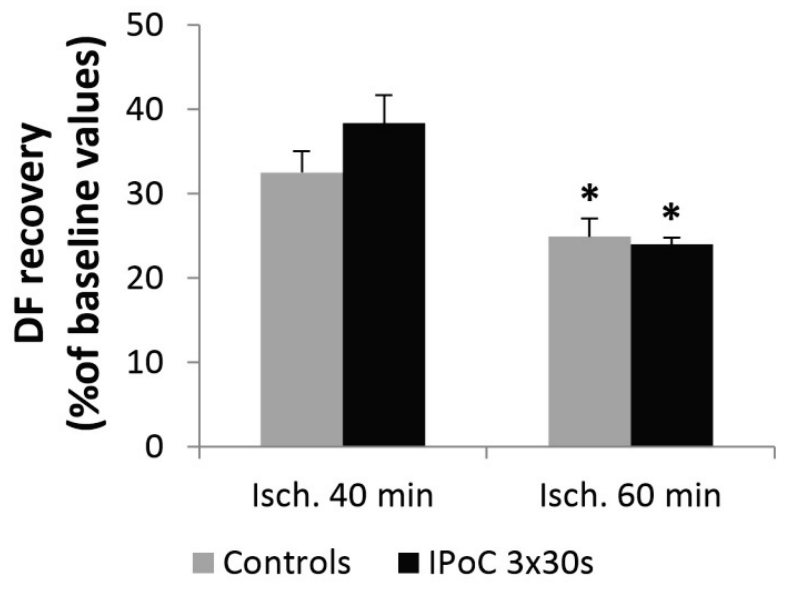

Fig. 4. Tolerance to ischemia (DF, expressed as the percentage of baseline values) and postconditioning (IPoC) after 40 and 60 min ischemia. * significantly different $(p<0.05)$ as compared to correspondent 40 min ischemia group.

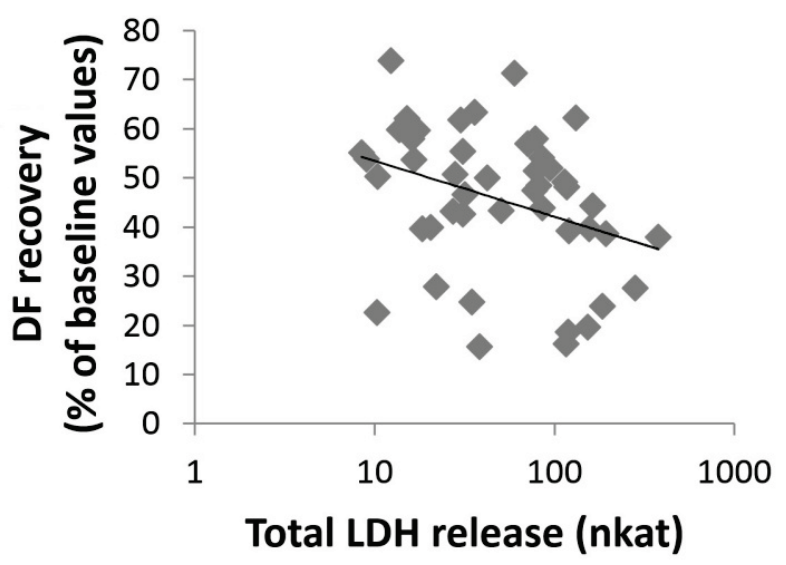

Fig. 5. Statistically significant correlation $(r=-0.36)$ of total $L D H$ release (nkat) and DF recovery (percentage of baseline values), $n=46$.

\section{Discussion}

The major result of this study is the observation that different protocols of ischemic postconditioning were unable to increase ischemic tolerance to oxygen deprivation during the first ten days of postnatal life. The data on LDH release confirm the inefficiency of ischemic postconditioning during early period of ontogenetic development. This finding slightly differs from the above mentioned developmental studies on the protective effect of ischemic preconditioning and adaptation to chronic hypoxia (Oštádalová et al. 1998, 2002), where the first signs of protection were observed already by the end of the first postnatal week. It suggests possible different timing of the development of the protective effect of ischemic postconditioning, repeatedly described in adults 
(for a review see Ovize et al. 2009). Therefore, we can suppose that the protection will occur somewhere between day 10 and adulthood. Unfortunately, our experimental setup of the immature isolated heart does not allow studying the older animals. Nevertheless, this question needs further analysis, particularly as far as the possible ontogenetic differences in the efficiency of the different protocols of ischemic postconditioning are concerned.

Ischemic postconditioning in the adult hearts is well described phenomenon. It has already been found in various organs other than heart (e.g. brain, Zhao et al. 2006) and has been successfully tested in clinical medicine (Staat et al. 2005). Possible mechanisms responsible for its protective effects include mitochondrial permeability transition pore (Argaud et al. 2005), mitochondrial K-ATP channels (Yang et al. 2004) or various protective kinases such as PI3K-Akt pathway (Tsang et al. 2004). To answer the question whether the mechanisms of the protective effect of ischemic postconditioning differs during ontogenetic development remains to be clarified.

Neonatal rat hearts are more resistant to ischemia. The comorbidities that adversely affect the adult heart, such as hypertension (Bešík et al. 2007), do not abolish this high neonatal resistance (Charvátová et al. 2012). Historically, many mechanisms were suggested to be responsible for high neonatal tolerance to ischemia. It is known that neonatal heart differs from adult heart in metabolic factors such as glycolytic capabilities (Hoerter 1976), amino acid metabolism (Julia et al. 1990), calcium metabolism (Boucek et al. 1984) or vascularization (Rakušan 1999). Moreover, the involvement of mitochondrial permeability transition pore has been suggested (Milerová et al. 2010) similarly as in the mechanisms of cardioprotection. Recently, Liaw et al. (2013) demonstrated that neonatal hearts exhibit greater Akt reserves available for phospho-activation compared with mature heart. Downstream a tone of the major effectors, neonatal hearts show the greatest degree of phospho-inhibition of glycogen synthase kinase $3 \beta$. In terms of postnatal changes of myocardial tolerance to oxygen deprivation, these data reveal a complex series of changes in pro-survival and pro-death proteins with maturation.

The unsuccessful attempts to increase cardiac tolerance to oxygen deprivation in neonatal rats suggest that we might be dealing with the more general biological phenomenon: the already high resistance of the cardiac muscle cannot be further increased by another protective mechanism. A similar situation as in the immature mammalian heart can also be observed in the highly tolerant hearts of poikilotherms (Overgaard et al. 2004) or in the myocardium of young females (for a review see Ošt’ádal et al. 2009b).

\section{Conflict of Interest}

There is no conflict of interest.

\section{Acknowledgements}

This study was supported by grants IGA NT 13358-4 and GAČR 13-01710S.

\section{References}

ARGAUD L, GATEAU-ROESCH O, RAISKY O, LOUFOUAT J, ROBERT D, OVIZE M: Postconditioning inhibits mitochondrial permeability transition. Circulation 111: 194-197, 2005.

BEŠÍK J, SZÁRSZOI O, KUNEŠ J, NETUKA I, MALÝ J, KOLÁŘ F, PIRK J, OŠŤÁDAL B: Tolerance to acute ischemia in adult male and female spontaneously hypertensive rats. Physiol Res 56: 267-274, 2007.

BOLLI R: Preconditioning: a paradigma shift in the biology of myocardial ischemia. Am J Physiol Heart Circ Physiol 292: H19-H27, 2007.

BOUCEK RJ, SHELTON M, ARTMAN M, MUSHLIN PS, STARNES VA, OLSON RD: Comparative effect ofverapamil, nifedipine and diltiazem on contractile function in the isolated immature and adult rabbit heart. Pediatr Res 18: 948-954, 1984.

CHARVÁTOVÁ Z, OŠŤÁDALOVÁ I, ZICHA J, KUNEŠ J, MAXOVÁ H, OŠŤÁDAL B: Cardiac tolerance to ischemia in neonatal spontaneously hypertensive rats. Physiol Res 61: S145-S153, 2012.

HOERTER J: Changes in the sensitivity to hypoxia and glucose deprivation in the isolated perfused rabbit heart during perinatal development. Pflugers Arch 363: 1-6, 1976. 
JULIA P, YOUNG PP, BUCKBERG GD, KORFSKY ER, BUGYI HI: Studies of myocardial protection in the immature heart. II. Evidence for importance of amino acid metabolism in tolerance to ischemia. $J$ Thorac Cardiovasc Res 100: 888-895, 1990.

LASKEY WK: Brief repetitive balloon occlusions enhance reperfusion during percutaneous coronary intervention for acute myocardial infarction: a pilot study. Catheter Cardiovasc Interv 65: 361-367, 2005.

LIAW NY, HOE LS, SHEERAN FL, PEART JN, HEADRICK JP, CHEUNG MM, PEPE S: Postnatal shift in ischemic tolerance and cell survival signaling in murine myocardium. Am J Physiol Regul Integr Comp Physiol 305: R1171-R1181, 2013.

LITCHTFIELD JB: Blood pressure in infant rats. Physiol Zool 31: 1-6, 1958.

MILEROVÁ M, CHARVÁTOVÁ Z, ŠKÁRKA L, OŠŤÁDALOVÁ I, DRAHOTA Z, FIALOVÁ M, OŠŤÁDAL B: Neonatal cardiac mitochondria and ischemia/reperfusion injury. Mol Cell Biochem 335: 147-153, 2010.

MUKHERJEE KL: Routine analysis of diagnostic enzymes Lactic dehydrogenase (LD). Med Lab Tech 3: 930-933, 2010.

OŠŤÁDAL B, KOLÁŘ F: Cardiac adaptation to chronic high-altitude hypoxia: beneficial and adverse effects. Respir Physiol Neurobiol 158: 224-236, 2007.

OŠŤÁDAL B, OŠTÁDALOVÁ I, KOLÁŘ F, CHARVÁTOVÁ Z, NETUKA I: Ontogenetic development of cardiac tolerance to oxygen deprivation - possible mechanisms. Physiol Res 58 (Suppl 2): S1-S12, 2009a.

OŠŤÁDAL B, NETUKA I, MALÝ J, BEŠÍK J, OŠŤÁDALOVÁ I: Gender differences in cardiac ischemic injury and protection - experimental aspects. Exp Biol Med (Maywood) 234: 1011-1019, 2009b.

OŠŤÁDALOVÁ I, OŠŤÁDAL B, KOLÁŘ F, PARRATT JR, WILSON S: Tolerance to ischemia and ischaemic preconditioning in neonatal rat heart. J Mol Cell Cardiol 30: 857-865, 1998.

OŠŤÁDALOVÁ I, OŠŤÁDAL B, JARKOVSKÁ D, KOLÁŘ F: Ischemic preconditioning in chronically hypoxic neonatal rat heart. Pediatr Res 52: 561-567, 2002.

OVERGAARD J, STECYK JA, GESSER H, WANG T, GAMPERL AK, FARRELL AP: Preconditioning stimuli do not benefit the myocardium of hypoxia-tolerant rainbow trout (Oncorhynchus mykiss). J Comp Physiol B 174: 329-340, 2004.

OVIZE M, BAXTER GF, DI LISA F, FERDINANDY P, GARCIA-DORADO D, HAUSENLOY DJ, HEUSCH G, VINTEN-JOHANSEN J, YELLON DM, SCHULZ R: Postconditioning and protection from reperfusion injury: where do we stand? Cardiovasc Res 87: 406-423, 2010.

RAKUŠAN K: Vascularization of the heart during normal and pathological growth. Adv Org Biol 7: 130-153, 1999.

RIVA A, HEARSE DJ: Age-dependent changes in myocardial succeptibility to ischemic injury. Cardioscience 4: 85-92, 1993.

SKYSCHALLY A, VAN CASTER P, ILIODROMITIS EK, SCHULZ R, KREMASTINOS DT, HEUSCH G: Ischemic postconditioning: experimental models and protocol algorithms. Basic Res Cardiol 104: 469-483, 2009.

STAAT P, RIOUFOL G, PIOT C, COTTIN Y, CUNG TT, L'HUILLIER I, AUPETIT JF, BONNEFOY E, FINET G, ANDRÉ-FOUËT X, OVIZE M: Postconditioning the human heart. Circulation 112: 2143-2148, 2005.

TSANG A, HAUSENLOY DJ, MOCANU MM, YELLON DM: Postconditioining: a form of „modified reperfusion” protects the myocardium by activating the phosphatidylinositol 3 kinase-Akt pathway. Circ Res 95: 230-232, 2004.

YANG XM, PROCTOR JB, CUI L, KRIEG T, DOWNEY JM, COHEN MV: Multiple, brief coronary occlusions during early reperfusion protect rabbit hearts by targeting cell signaling pathways. J Am Coll Cardiol 44: 1103$1110,2004$.

ZHAO ZQ, CORVERA JS, HALKOS ME, KERENDI F, WANG NP, GUYTON RA, VINTEN-JOHANSEN J: Inhibition of myocardial injury by ischemic postconditioning: Comparison with ischemic preconditioning. $\mathrm{Am}$ J Physiol Heart Circ Physiol 285: H579-H588, 2003.

ZHAO H, SAPOLSKY RM, STEINBERG GK: Interrupting reperfusion as a stroke therapy: ischemic postconditioning reduces infarct size after focal ischemia in rats. J Cereb Blood Flow Metab 26: 1114-1112, 2006.

ZICHA J, KUNEŠ J, JELÍNEK J: Experimental hypertension in young and adult animals. Hypertension 8: 1096-1104, 1986. 